\title{
Not Just for Boys: Good Pedagogy is Good for All
}

Scott Hughes

\author{
Vancouver School Board
}

\begin{abstract}
This conceptual paper examines the education of boys through the filter of pedagogy and goodness. In this paper, I posit a distinction between instructional strategies (the toolkit of practical activities and strategies used to support children's learning) and pedagogy (the relational and practical response to the needs of children in the lived moments of teaching). Through a discussion of the role model hypothesis, which posits that likegender teachers are good for like-gender students, I argue that it is not only a teacher's gender but also a teacher's non-gendered human qualities such as fairness and kindness that are most relevant to students' learning. This paper concludes with discussion on strength and masculinity as being multi-dimensional constructs, and considers the notion of good pedagogy, which endeavours to place a multiplicity of all boys' and all girls' ways of being at the centre of practical and pedagogical thinking in order that they may flourish fully at school and in learning.
\end{abstract}

Keywords: gender; pedagogy; goodness; instructional strategies; role model hypothesis 


\section{Not Just For Boys: Good Pedagogy is Good For All}

"Come; let us live in exemplary fashion for the benefit of our children." (Froebel, as cited in Brosterman, 1997, p. 27)

"Strong and healthy boys are made strong by acceptance and affirmation of their humanity.” (Kindlon \& Thompson, 1999, p. 258)

I have just finished reading a number of articles about hegemony, masculinity, and the concern that elementary schools are failing its boys, and I am left perplexed. The general tenor of the argument about educating boys in contemporary society goes something like this: "Everyone panic! Boys are losing the race; we are constructing hegemonic masculinity in hyper-feminized elementary schools where the only writing topic allowed is fairies and flowers." The argument continues: "Elementary schools are hyperfeminized, which does a disservice to the boys; further, funds spent in the 1990s to get the girls 'gung-ho' about maths and sciences have left the boys behind. Girls are dominating the intellectual playground while boys are left mucking about in the sand box! Let's pull together a strategic recruitment plan to 'Get more guys teaching kindergarten!' We need more male role models in our elementary schools! We need 'more fathers!'"

Please forgive this cheeky opening paragraph. It reflects a personal aversion to the oversimplification of matters of gender in education. Understanding the contexts and ways gender shapes children's experiences of school and learning is a necessary and important conversation. Yet, as a gay male teacher of young children, I am perplexed by the notion that there is one particular way to teach boys-often typified as involving their bodies or jocular humour-and that this is different than the way girls should be taught. In my experience, all children enjoy lively and embodied instruction and learning experiences, not just boys. Further, as a man who avoids being held captive by stereotypical notions of what it means to be a man, I seek ways of thinking about pedagogy that will broaden my ways of being as a teacher of young children, towards creating classroom spaces that are welcoming, kind, and respectful.

Accordingly, this conceptual paper explores intersections between gender and pedagogy. Specifically, this paper considers pedagogy and its relationship to the education of boys as being a more complex construct than a simple set of boy-friendly instructional strategies. As Martino (2008) asks, "Which boys are we talking about?” (p. 1). My experience is that there are many ways to be a boy; my aim is to contribute to educational literature that affirms this multiplicity. Finally, I will weave in observations of gender and education from my work as a classroom teacher. Connelly and Clandinin (1990) state, "Education is the construction and reconstruction of personal and social stories; teachers and learners are storytellers and characters in their own and other's stories” (p. 2). They point out that the use of story and narrative in educational research serves as both phenomenon and method, in that our stories help to name the phenomenon of lived experiences, and that the narratives that result from inquiry into our stories help us characterize and understand this lived experience in new and meaningful ways. Consequently, although I do not position this paper as a narrative inquiry in the formal sense, I acknowledge that my lived experience as being male, gay, and a teacher of young children deeply informs this paper about gender, pedagogy, and education. 


\section{Instruction and Pedagogy}

There is a growing body of literature exploring the education of boys in the elementary grades (e.g., Gosse, 2011; Holmlund \& Sund, 2008; Johnson \& Weber, 2011; Martino, Lingard, \& Mills, 2004). Weaver-Hightower (2003) calls this shift in research the "boy turn" (p. 472); he means this both as a turn in movement towards boys and their experiences of schooling, and as means to point out that boys are now "due" their turn for consideration in ways not previously granted. Weaver-Hightower (2003) outlines four major categories of what he calls the "boy turn research literature" (p. 474): popular, theoretical, practitioner, and the feminist and pro-feminist responses. Although each of these categories offers a nuanced way of understanding gender and education, WeaverHightower points out that, for the most part, the underlying arguments supporting each of these categories are based on a boy versus girl mode of binary thinking. Though WeaverHightower broadly covers a range of political views and voices, both contributory and contentious, in the field of the education of boys and highlights numerous studies that explore gender and education, few specifically consider the relationship between gender and pedagogy. Rather, the majority focus on theoretical constructs of gender, such as masculinity (e.g., Renold, 2001; Skelton, 2001) or instructional strategies used to address neurological and biological differences in boys and girls (e.g., Gurian \& Stevens, 2011; James, 2007).

Instructional strategies are the practical approaches that teachers use to teach students the skills and content knowledge that curriculum documents and student-need dictates. Instructional strategies aimed at engaging boys in the classroom often draw upon a singular notion of what a boy is, and calls for strategies based on stereotypical interests of boys, such as reading comic books or the humorous adventures of Captain Underpants to develop their literacy skills (Marisuo-Storm, 2006). Though such strategies might engage some boys, there is a critical awareness that such strategies are simplistic in nature and fail to address the many different interests, natures, and ways of being a boy (Alloway \& Gilbert, 2002; Martino \& Pallotta-Chiarolli, 2003; Weaver-Hightower, 2003).

Although instructional strategies are an important part of a classroom teacher's toolkit, questions of pedagogy that drive decisions to choose this or that strategy are not just the questions of what to teach and how to teach it, but also the deeper questions of why teachers teach what they teach and who it is they are teaching (Palmer, 1998, Smithrim, 2000). Pedagogy, then, involves teachers asking themselves questions about both who they are as teachers and who their students are. Asking who questions of learning and instruction transforms classroom work from being a strategy-based practice to being a relational one. Dewey (1897) reminds us that pedagogical action stems from observing children and developing insights into their capacities, interests, and habits. In this way, pedagogy is deeply social. Palmer (1998) echoes Dewey by stating: "Good teaching cannot be reduced to technique; good teaching comes from the identity and integrity of the teacher" (p. 10). Thus, pedagogy is a relational endeavour, with the aim of forging positive relationships between teachers and students (Bingham \& Sidorkin, 2004; Margonis, 2004). 
van Manen (1991, 2002) conceptualizes pedagogy as a relational sphere that coexists between adults and children. He writes:

Pedagogy first of all refers to our everyday living with children as parents, teachers, school principals, guidance counsellors, educational psychologists, child care workers, and so on. And pedagogy refers to our need to reflect on our pedagogical living with children. (van Manen, 1991, p. 41)

He further asserts that pedagogical action is, at once, thoughtful, reflective, and responsive to children. He claims, "Pedagogical thoughtfulness is sustained by a certain kind of seeing, of listening, or responding to a particular child or children in this or that situation” (van Manen, 2002, p. 10). Through seeing children for who they are, and striving to know their interests, fears, development, and ways of being, teachers are informed about how to best respond to children, practically, in the lived moments of classroom life. Further, van Manen reminds us that good pedagogy is conditioned by our sense of love, care, hope, and responsibility for children. It is this conception of pedagogy as being a caring, thoughtful, practical, and relational response to children that frames this paper.

\section{Role Modelling}

Teachers hold a special responsibility in the lives of children. How teachers act, the topics they discuss, the passions they share, and the essence of who they are with children can shape children's experience of school in both positive and negative ways. As a teacher with many years of experience in the primary classroom, I am reminded of many conversations I have had with parents who observe and share the stories of how their children adopt new turns of phrase, gestures, or interests as a result of being in my class. Sometimes, I experience this as a compliment, such as a story about a child who goes home and recites a newly memorized poem or expresses a new-found interest in cooking (poetry and cooking are two passions that I bring to the classroom), and sometimes I cringe, such as when a parent relays a story of their child bossing their younger sibling about at home as they "play" at school. Such everyday classroom situations offer opportunity for pedagogical reflection. Am I really that bossy? What tone of voice have I been using most recently as I give directions in the classroom? What are the passions of my students that I might support? How might I best model and encourage thoughtful, caring behaviours in the classroom? And, in what ways does my gender shape my pedagogical responses to children?

In gender-based research, pedagogy typically is translated into the idea of role modelling (Ascher, 1991; Bricheno \& Thornton, 2007; Chmelynski, 2006; Roulsten \& Mills, 2000; Solomon, 1997). The underlying argument of research into role modelling is that male teachers will best shape the development of masculine identities in students (Davison \& Nelson, 2011; Johnson \& Weber, 2011); this notion is also supported in popular literature (Sax, 2007; Tyre, 2008). For example, Gosse (2011) describes a Canadian online public opinion poll in which $59 \%$ of the votes (7285 of 10,502)

disagreed with the statement, "The gender of a teacher makes no difference to learning outcomes for boys" (p. 117). In other words, according to the participants of this poll, the gender of a teacher does matter to the education of boys. In contrast, research has also 
identified that it is not gender but rather human characteristics such as good humour and kindness that matter most to children (Lahelma, 2000; Lingard, Martino, Mills, \& Barr, 2002; Smithrim, 2000).

Carrington, Tymms, and Merrell (2008) call this relationship the role model hypothesis, which posits that children identify more readily and learn better with teachers of the same gender (see also Carrington et al., 2007). This hypothesis echoes a wealth of research in the 1980s and 1990s, which examined the positive impact that teachers of colour have on their students who share the same social, cultural, and racial characteristics (e.g., Allen, 1990; Evans, 1992; Graham, 1987; Irvine, 1989; Stewart, Meier, \& England, 1989). More recent studies have identified that in classrooms where teachers and students share the same racial characteristics, students demonstrate an increased level of trust and respect for their teachers, a boost in self confidence, and a diminishment in perception that they might be racially stereotyped by a different teacher, one who does not share the same racial or cultural background (Dee, 2004; Noguera, 2003). It has been argued that, due to the increasing cultural diversity of school populations, especially in urban environments, teachers of colour are in a unique position to positively influence and inspire students; accordingly, fair and equitable programs to increase the numbers of visible minority teachers at both the preservice and in-service levels will go a long way towards providing all students with positive role models (Ryan, Pollock, \& Antonelli, 2009). Rezai-Rashti and Martino (2010), however, critique the role model hypothesis, arguing that supposed "exemplary" models of race and gender are commonly based on idealized and two-dimensional representations, and thus fail to fully address the complexities of race, gender, and sexuality that are lived and expressed in our schools.

In the literature reviewed for this paper, two differing perspectives on what matters in the education of boys emerged: children's perspectives and adults' perspectives. These two perspectives are outlined below. Although the studies described are from a variety of countries (i.e., Canada, England, Finland, USA, and Australia) and thus need to be read with a sense of caution in their applicability to the Canadian context, they do serve to highlight important points of consideration that are applicable to a conversation about pedagogy that is informed by a relational framework of thinking.

\section{Children's Perspectives on Role Modelling}

In response to an increased awareness about the lack of male teachers in the primary grades, Carrington et al. (2007) conducted a qualitative study investigating whether children experience differences in how male and female teachers' respond to them during the school day, and whether children see themselves as relating better to teachers of the same gender. This study was conducted in 51 Year 3 classes in England (i.e., 7- to 8-year olds, or the Canadian equivalent of Grades 2 and 3); data were collected through classroom observations, and semi-structured interviews with teachers and students. Carrington et al. (2007) unpack the claim that the "feminization" of primary schools and the lack of male role models is bad for boys. Based on their research, they conclude that this is not the case. They state: "For the majority of the children, the gender of the teacher was largely immaterial. Students valued teachers, whether men or women, who were consistent and even-handed and supportive of them as learners" (Carrington et 
al., 2007, p. 397). It is my observation that these qualities of consistency and evenhandedness are qualities of good pedagogy. The children in this study were able to identify these qualities not because their teacher was a man or a woman, but because their teachers were pedagogically thoughtful and responsive to their learning needs. As Carrington et al. (2007) note: "The voices of the children in our study are clear: it is the teacher's pedagogic and interpersonal skills that are vital in engaging them as learners, regardless of their gender” (p. 412).

In a subsequent study, Carrington, Tymms, and Merrell (2008) explored the role model hypothesis by investigating the impact that same gender teachers have on the attitudes to learning amongst boys and girls. This quantitative study analyzed data collected from a cohort of 8978 children in English primary schools, comprised of 413 separate classes for 11 year-olds. Of these, 113 of the classes were taught by males and 300 of the classes by females. Participants completed tests designed to determine attainment levels in reading, maths, science, and English vocabulary, as well as answering questionnaires designed to elicit children's attitudes both to learning subject matter and to school in general. Commensurate with the above findings, this study "found no empirical evidence to support the claim that there is a tendency for male teachers to enhance the educational performance of boys and, conversely, for female teachers to enhance the educational performance of girls" (Carrington, Tymms, \& Merrell, 2008, p. 321). Supporting the strength of these findings, Carrington et al. (2008) reviewed four large-scale studies investigating the impact that teacher gender has on the students' motivation, engagement, achievement, and perceptions of quality of teaching (i.e., Ehrenberg, Goldhaber, \& Brewer, 1995; Lahelma, 2000; Lingard, Martino, Mills, \& Barr, 2002; Martin \& Marsh, 2005). These four studies reported that students most consistently valued teachers who exhibited traits and behaviours - such as fairness, consistency, and humour- "which [are] not considered to be the domain of either gender" (Carrington et al., 2008, p. 317).

In a Finish ethnography, Lehelma (2000) explored children's perceptions of male and female teachers and, in doing so, revealed personal qualities that are not gender dependent and are vital to creating conditions that support children's success in school. Two sets of interviews of 90 children were conducted in which participants were asked which of their teachers and what kinds of teachers they liked and disliked. Participants were also asked to describe their ideal teacher. Children described their ideal teacher as being one who demonstrates characteristics such as fairness, a sense of humour, considerateness, and gentleness. The findings revealed that "gender did not appear to be relevant when young persons talked about teachers” (p. 173).

Considering this finding-that children are most responsive to non-gendered teacher traits such as good humour and fairness - compels me to reflect upon the ways in which my gender informs my practice as a teacher of young children. I am in the unique position of being a man in a profession that is traditionally associated with women. I have come to recognize that my choice as a young man to step outside of traditionally-held male professions of dominance, such as a competitive model of conducting business, has afforded me the privilege of finding new ways to be a man and to engage in relational, caring work. Further, as a young teacher, I had a heightened sensitivity to matters of touch and a fear that I was not afforded the same gestures of care that my female 
colleagues were able to extend to children. As I have matured in my practice this fear has dissipated; I have learned how to extend care and compassion to young children in ways that attend to children's needs as is appropriate to my role as their teacher.

I recognize that the ways I extend care to my students are not the only ways in which I shape, consciously or not, their notions of masculinity. In my youth, I was a competitive figure skater and downhill skier, but I shied away from ball and team sports. As a result, I consider myself to be athletic but not in the least bit sporty. I have no interest in hockey or football. Further, I have spent my life actively engaged in the arts and am easily dazzled by good design. Thus, as a teacher, I bring a passion for the arts and athletics to the daily experiences of my students. This is a delight for some of my students, with whom I will happily fold glittery fabric into a neat bundle as we tidy-up after playtime.

Yet for other students I suspect that who and how I am causes a certain degree of puzzlement: I look like a man (I am tall, and scruffy when I don't shave), but I don't always talk like a man (I do not engage in jocular conversation about sporting events). Despite my wish to avoid stereotypes of masculinity by being a man of diverse expressions, and through developing a classroom program that is responsive to all of my students' interests and ways of being, I recognize that my own lack of interest in (and/or ability to) engage in traditionally held ways of being masculine limits my pedagogical responsiveness. Even in my attempts to be broad reaching for my students, I fall short of the needs and interests of some of them. Thus, I am challenged every day to extend to my students an interest in things in which I might not otherwise be interested. Further, I am reminded that who I am as a human-as expressed through gestures of care, compassion, good humour, and kindness - are the characteristics that I find my students are most responsive to, and the ones I am most interested in cultivating within myself. Thus, my way of being male, as expressed by the ways in which I consciously or unconsciously subvert or conform to my students' notions of masculinity, is an unspoken subtext in our daily learning experiences.

\section{Adults’ Perspectives on Role Modelling}

Though children indicate that characteristics such as humour and fairness are of central importance when asked to reflect on what they think makes a "good" teacher, it is adults who recognize and articulate the need for positive male role models and the ways in which gender shapes children's experiences of schooling. Research has found that at the high school level, the presence of a like-gender teacher in the classroom (a) raises the achievement scores of the like-gender student in the core subject areas of science, social studies, and English, (b) facilitates improved communication, and (c) increases motivation and (d) shifts the perception of whether a particular behaviour is problematic or not (e.g., expressions of humour might be perceived to be a problem by a female teacher but not by a male teacher) (Dee, 2006). In contrast, an Australian study examining the impact of teacher gender on 964 junior and middle schools students' motivation and test-score outcomes in core subject areas found little support that gender impacts on students, but rather that it is "the nature of pedagogy that is critical and not the gender of the person delivering it” (Marsh, Martin, \& Cheng, 2008, p. 91). 
In the Canadian context, Gosse (2011) identifies ways in gender does impact on student learning. In a qualitative study of Ontario male teachers certified to teach the Primary/Junior grades, Gosse analyzed the responses that 223 male teachers gave to an on-line survey, which asked participants to comment on their experiences of being a male teacher of young children. Through a thematic analysis of quotations containing the term "role model," Gosse found that male teachers serve as positive role models with regards to race, sexual orientation, and culture. Gosse (2011) argues that because our human contexts of gender, race, class, and ability contribute significantly to student success and learning, there is the increasing need to promote diversity "beyond the confines of gender” (p. 132) within our teaching populations.

\section{Discussion}

The lack of positive, mature, male role models and the socialization of boys in contemporary society is a well-documented narrative in popular literature (Kindlon \& Thompson, 2000; Newkirk, 2002; Whitmire, 2010). Cross (2008) coins the term boy man to describe the typical representation of a man that is represented frequently in the media - this representation being a man as someone who has never quite matured out of an adolescent way of being. Cross (2008) strongly states:

The issue of modern immaturity goes beyond the jeremiads of the left or the right. It goes to our embrace of a commercial culture that feeds on stunted human growth and to our society, which is fixed narrowly on living for today...the boyman has become a central character in our culture and, even if men do find ways of meeting their economic and even social obligations, the culture of immaturity has become the norm rather than the exception. (p. 2)

As observed by Cross, the current hegemony of the North American Guy, and those who represent him, is a little bit dodgy. As examples, I offer the role models of Homer Simpson, rap musicians who speak hateful words of violence against others, and that ever-pissed-off, eternally stubbled guy who never smiles - the guy frequently seen displayed in multiple forms of popular media, such as magazine covers, billboards, and television advertisements.

Moss (2011) argues that men define their masculinity through the consumer choices they make, such as the cars they drive, the underwear they choose to purchase, and the cologne they wear. In contemporary media and popular culture, there are a wide variety of masculinities being modeled. Moss (2011) describes these templates of masculinity as being a panoply of “avatars" (p. xviii) available for boys and men to copy, try on for size, and model themselves after. Moss (2011) notes, "Men today are contradictions and anomalies, characterized by extreme disparities of masculinities" (p. xiv). He argues that, despite this wide range, there remains a strong pressure for boys and men to adopt traditional masculine characteristics.

As an adult, I can view media-based representations of traditional masculinities critically. I understand that such models are in Guy Drag, acting a parody of hypermasculinity, selling a product or a fantasy of who men should be. I am old enough to understand the irony of such images and role models and, hopefully, to not be swayed by them. However, my experience has taught me that children do not have the same 
developed critical powers of thinking as adults do, and they do not understand irony. Boys might mimic a vocabulary of irony, but they do not, objectively, see themselves as separate from all of this. They see themselves as a direct participant in the greater culture of Guy and, in turn, try to emulate it.

This representation of being a man is concerning not just because of it might teach boys, but also because of what this is potentially teaching boys and girls about being a person and about how to socialize and interact with others in their families, schools, and communities. It is concerning because of what this potentially teaches young children about how to behave and socialize with each other. It is concerning because such representations of masculinity do not represent a range of possibilities of how to be a man. Thus, children do need positive role models. Children need positive, life-affirming male role models who demonstrate that one can be a happy, caring, thoughtful, sensitive man in consideration of others. But caring, consideration, and compassion have nothing to do with gender. They are the landmarks of someone, regardless of their gender, who simply aspires to be a good and kind person.

My intent is not to devalue the work encouraging men to join the profession of teaching young children, or to negate the value of investigating the role that gender plays in shaping experiences of teaching and learning: I applaud this work. Rather, my intent is an increased understanding of the areas and instances where gender is important in classroom work. Understanding gender is important to the practical response to children's learning needs, such as choosing specific literature or planning certain activities that appeal to a wide range of boys and girls and their interests in the classroom. Indeed, designing a classroom program that draws upon a wide range of instructional strategies is unquestionably vital in the engagement of all children at school.

In today's diverse schools and communities, good teaching practice includes establishing a safe and inclusive learning environment in which race, gender, sexuality, and ethnic diversity is acknowledged. Gender might inform a response when inside a pedagogical moment-such as how to best support a boy who is being teased by classmates for playing with a glittery crown in the dress-up centre, or welcoming a child with two fathers into the classroom. And, understanding ourselves as gendered beings across a spectrum, and our resulting tacit and explicit participation in gender inequity, both historical and contemporary, helps us to behave in more socially responsible ways. Behaving in a socially responsibility way can only help towards making our schools and communities a better, more just place to be. But, evidence suggests that gender is not as important to teacher pedagogy and, more importantly, to children's lived experiences of teacher pedagogy. Key to student success and achievement is a pedagogical thoughtfulness, framed by personal qualities of goodness (e.g., fairness consistency, and humour), and supported by respectful relationships.

Following the literature presented above, I argue that pedagogy is not a gender dependent construct. Pedagogy is not about more or less of this or that instructional strategy for girls or boys, or for the women, men, and children who bravely claim their place on the spectrum of gender. Rather, pedagogy is about building good relationships that foster the learning and personal development of students whether or not the teacher is male or female or the student is a boy or a girl. Thus, if teacher gender is largely 
secondary to children and it is adults who are primarily concerned about providing positive role models for children, how does that help educators reframe the conversation about educating boys? How might this help educators move beyond a "one-size-fits-all approach to improving boys' underachievement” (Martino, 2008, p. 3), such as offered by simplistic strategies that appeal to a stereotypical notion of a boy, towards the complex nuances of enacting a pedagogy of goodness in service to and with all children?

In asking this question, I acknowledge that the term goodness is a subjective one, raising the question of "goodness according to whom?" Goodness can be associated with moral and affective dimensions of human experience, such as beauty, truth, and love (Winston, 2006). In this way, I use the term goodness in relation to pedagogy for its ability to evoke in ourselves an ephemeral and empathic sense of responsibility for children, one that is held by thoughtful, caring teachers.

In responding to the question of how to move towards enacting a pedagogy of goodness that is responsive to all children, it is necessary to look both within and beyond schools, and across social institutions, to find ways of reframing masculinity and the role models in the lives of boys and male youth. Anderson (2009) looks broadly at the social construction of masculinity over the past half-century within Anglo-American society, describing three distinct periods: (a) elevated homohysteria, (b) diminishing homohysteria, and (c) diminished homohysteria. Each period is defined by a heightened or diminished relationship to the fear of being homosexualized, what he calls homohysteria. He argues that homophobic discourse, such as found in men's locker rooms, is the most central means of policing masculinity. He further argues that in contemporary Anglo-American society - a time of diminished homohysteria - there are two central expressions of masculinity: orthodox and inclusive. Orthodox masculinity is characterized by homohysteria, alongside physical and emotional distance between and amongst men. Inclusive masculinity is characterized by a comfort with a wide spectrum of masculinities and sexual and gender orientations. Anderson asserts that there is hope for men who wish to reach beyond an orthodox expression of masculinity, one that is constrained by homohysteria, for it is through a proliferation of multiplicity that the hegemony of a singular masculinity, as defined by homohysteria, dominance, and distance, is transformed to something more inclusive.

In order to consider Anderson's (2009) discussion of masculinity in an educational setting, I will consider Sax's (2007) definition of a man. He states that a man is "someone who uses their strength in service of others" (Sax, 2007, p. 181). Living in service of others requires empathy: the ability to recognize that the experiences and needs of others are real and valued. An empathic response to others requires one to develop a wide repertoire of human values such as care, compassion, a sense of ethical responsibility, and selflessness. Living in service of others requires the recognition of a greater good beyond ourselves, and the recognition of how we might as individuals contribute to this greater good. We can serve others when we recognize that we are not alone in this world, that we are all connected to each other, and that we each have something valuable to contribute to our communities.

To help contextualize his description of qualities that make a man, Sax (2007) presents the case of an all-American boys prep school that takes senior students on an 
annual volunteer work program to a poor community in rural South America. This example highlights the value of volunteer work - how it might promote empathy and foster ethical decision making in youth. I recognize that this case can also be construed as a story of privilege and colonization, one that reinforces the notions of other and the divides of economic advantage, for it positions the prep-school boys as heroes, doing a good deed for those less fortunate, knowing all the while that they will be able to return home to their comfortable life. Thus, this example also raises the question, "Who does such service learning actually serve?" Though unpacking this question is outside of the scope of this paper, it remains an important point of consideration for teachers and schools who are working to create opportunities that teach their students how to act in socially responsible ways in service to their communities.

Returning to the Sax (2007) example, the boys (as volunteers) help the community build homes and run their farms, all without the advantage of modern conveniences such as flush toilets and the Internet. The headmaster from this school makes the following comment about how this experience teaches the students about service to others: "There's nothing like putting a shovel in a boy's hands to teach him some lessons” (p. 182). This echoes Anderson's (2009) description of orthodox masculinity. Demanding physical experiences and the opportunity to experience other cultures and ways of being are, without question, an excellent way to help boys and young men develop a sense of service and caring for others. Having such experiences can teach boys about their limitations and strengths, and help them to discover a new capacity to push themselves beyond what they imagined to be possible. These are profoundly important life lessons in becoming human.

Sax’s (2007) central argument is that a man is defined by the use of his strength in service to others. In offering this definition, Sax does not expand upon a definition of a range of strengths that men might draw upon. The concern with reducing strength to only its physical description has the potential to land a discussion of masculinity into a onedimensional and orthodox stereotype of manliness: action over reflection, confidence in the face of risk, emotional distance, and unsmiling facial expressions (Mansfield, 2006). In turning to the example of boys with shovels in their hand, he sets up a potentially limiting definition of strength to a singular interpretation of physical strength. Physical strength is, without question, one facet of masculinity, but it is not the only one and not the one that every man need necessarily have.

Strength, like Anderson's (2009) description of inclusive masculinity, is multidimensional. Human strength can be emotional, spiritual, artistic, intellectual, or physical, among others. I find Sax's (2007) observation that a man is someone who "uses [his] strength in service of others" to be helpful in thinking about pedagogy and goodness. However, I would broaden the meaning of the words strength and service to embrace the notion that being a man means arriving at a place in himself where he recognizes his own unique strengths and how he might best use them to be in service of others. Considering good teaching in terms of strength and service to children helps return us to van Manen's (1991) conception of pedagogy. Van Manen argues that pedagogy is about selfknowledge in relationship to and with children. Pedagogy is about knowing one's personal history, stories, beliefs, values, strengths, gender, and human frailties, and how this knowledge informs a practical response to a child in the lived moments of teaching 
and learning. Thus, as teachers who cross a broad spectrum of gender, we engage in pedagogical reflection because we are propelled by our love and care for children, and our concern for their healthy development. When we position children where they belong in this conversation about gender and education - in the centre-we cannot help but strive toward being, as van Manen observes, pedagogically in service to children.

\section{Implications for Research}

My experience as a classroom teacher has taught me that developing positive relationships with children (as with all human relationships) can be challenging, engaging, inspiring, rewarding, and just plain hard work. Being with children involves the internal work of continuously sending up for review previously held beliefs and values as children confront us with their own ways of being and seeing the world. Additionally, being with children involves the embracing the external forces of glitter and glue, of line-ups, coat hooks, and bells, and that particular frenzy that can only be experienced in a room full of costumed 5- and 6-year-olds on October 31 of each year. Being a good teacher, for me, involves the integration of teacher technique (my toolbox of curricular knowledge and instructional strategies), the inclination towards pedagogical thoughtfulness and care, and an on-going attempt to be simply a good person for students. If research on the education of boys in the past twenty years has focused largely on the social and critical aspects of constructing masculinity, the practical aspects of teacher technique in order to bolster boys' underachievement, and policy-makers charge to encourage more men teaching young children, what, then, are new questions to consider? I think new questions lie in the integrated domains of pedagogy, care, goodness, and how to best support boys as they develop into strong, caring men. I think turning to children to learn about their perceptions and experiences will reveal further insights. Freeman and Mathison (2009) offer philosophical, ethical, and practical insights into qualitative research with children. These insights include building trust with students by stepping outside of preset adult roles in the school, and using developmentally appropriate methods to elicit verbal and visual responses such as photo-elicitation, puppets, drawing, and role-drama.

\section{Good Pedagogy}

As Dewey (1897) points out, pedagogy is deeply responsive to the flourishing of an individual, one who is embedded within their social community. In this way, good pedagogy enables someone to become who they are meant to be, not because they are male or female, but because that is the most right thing for them to do. The result of this form of pedagogy is someone who is free to consider how they might best contribute their unique talents to their schools, communities, and society. I am talking about a thought pattern such as, "I want to become a kindergarten teacher." Full Stop. No gendered qualification. No gendered rationalization, such as, "I am a young man and I would like to become a kindergarten teacher, but I am told that is women's work, but that is cool, I will become a kindergarten teacher anyway.” Further, I am talking about a societal response that fully endorses this decision without defaulting to any singular stereotype or belief about what men and women ought or ought not to do or about who children might become as they live into their own unique future. 
This final piece is important. Good pedagogy supports children grow into their own unique future, in their own unique way. When we strip away conflicting ideas around educational questions of what, how, and why to teach, we arrive at the questions of who we are as teachers, and who the children are as our students. van Manen (2002) reminds us that the power of pedagogy lies in the daily gestures and tone of voice that we express as teachers, gestures that communicate important messages to children about their value as human beings. We are role models to children through the ways in which we are, simply, ourselves. In this way, he argues, we see our students through our bodies. van Manen (2002) states: "To really see a child is to give that child his or her place in specific time and space” (p. 31). Thus, to see children fully means to recognize that there are multiple ways of being gendered, and that we are all unique, each in our own strong, multi-dimensional, and complex way. We each have our own story to tell; supporting children as they tell their story, free from the limitations of labels and free from singular, limiting notions of what a boy or girl should or should not do, is the stuff of good teaching. And that is the stuff of good pedagogy. 


\section{References}

Allen, A. L. (1990). On being a role model. Berkeley Women's Law Journal, 6, 22-42.

Alloway, N., \& Gilbert, P. (2002). Boys and literacy learning: Changing perspectives. Watson, Australia: Australian Early Childhood Association.

Anderson, E. (2009). Inclusive masculinity: The changing nature of masculinities. New York, NY: Routledge.

Ascher, C. (1991). School programs for African-American male students. Equity and Choice, 8(1), 25-29.

Bingham, C., \& Sidorkin, A. M. (2004). The pedagogy of relation: An introduction. In C. Bingham \& A. M. Sidorkin (Eds.), No education without relation (pp. 1-7). New York, NY: Peter Lang.

Bricheno, P., \& Thornton, M. (2007). Role model, hero, or champion? Children's views concerning role models. Educational Research, 49(4), 383-396.

Brosterman, N. (1997). Inventing Kindergarten. New York, NY: Harry N. Adams.

Carrington, B., Francis, B., Hutchings, M., Skelton, C., Read, B., \& Hall, I. (2007). Does the gender of the teacher really matter? Seven- to eight-year-olds' accounts of their interactions with their teachers. Educational Studies, 33(4), 397-413.

Carrington, B., Tymms, P., \& Merrell, C. (2008). Role models, school improvement and the 'gender gap' - do men bring out the best in boys and women the best in girls? British Educational Research Journal, 34(3), 315-327.

Chmelynski, C. (2006). Getting more men and blacks into teaching. Education Digest, 71(5), 40-42.

Connelly, F. M., \& Clandinin, D. J. (1990). Stories of experience and narrative inquiry. Educational Researcher, 19(5), 2-14.

Cross, G. (2008). Men to boys: The making of modern immaturity. New York, NY: Columbia University Press.

Davison, K. G., \& Nelson, B. G. (2011). Men and teaching: Good intentions and productive tensions. The Journal of Men's Studies, 19(2), 91-96.

Dee, T. S. (2004). The race connection: Are teachers more effective with students who share their ethnicity? Education Next, 4(2), 52-59.

Dee, T. S. (2006). The why chromosome: How a teacher's gender affects boys and girls. Education Next, 6(4), 68-75.

Dewey, J. (1897). My pedagogic creed. The School Journal, 54(3), 77-80. Retrieved from http://playpen.meraka.csir.co.za/ acdc/education/Dr_Anvind_Gupa/Learners_Libra ry_7_March_2007/Resources/books/readings/17.pdf 
Ehrenberg, R. G., Goldhaber, D. D., \& Brewer, D. J. (1995). Do teachers’ race, gender, and ethnicity matter? Evidence from the National Educational Longitudinal Study of 1988, Industrial and Labour Relations Review, 48, 547-561.

Evans, M. O. (1992). An estimate of race and gender role-model effects in teaching high school. The Journal of Economic Education, 23(3), 209-217.

Freeman, M., \& Mathison, S. (2009). Researching children's experiences. New York, NY: Guildford Press.

Gosse, D. (2011). Race, sexual orientation, culture and male teacher role models: "Will any teacher do as long as they are good?” The Journal of Men's Studies, 19(2), 116-137.

Graham, P. A. (1987). Black teachers: A drastically scarce resource. Phi Delta Kappan, 68(8), 598-605.

Gurian, M., \& Stevens, K. (2011). Boys and girls learn differently: A guide for teachers and parents (10th ed.). San Francisco: Jossey-Bass.

Holmlund, H., \& Sund, K. (2008). Is the gender gap in school performance affected by the sex of the teacher? Labour Economics, 15(1), 37-53.

Irvine, J. J. (1989). Beyond role models: An examination of cultural influences on the pedagogical perspectives of Black teachers. Peabody Journal of Education, 66(4), 51-63.

James, A. N. (2007). Teaching the male brain: How boys think, feel, and learn in school. Thousand Oaks, CA: Corwin Press.

Johnson, S. P., \& Weber, B. R. (2011). Towards a genderful pedagogy and the teaching of masculinity. The Journal of Men's Studies, 19(2), 138-158.

Kindlon, D., \& Thompson, M. (1999). Raising Cain: Protecting the emotional life of boys. New York, NY: Ballantine Books.

Lahelma, E. (2000). Lack of male teachers: A problem for students or teachers? Pedagogy, Culture \& Society, 8(2), 173-186.

Lingard, B., Martino, W., Mills, M., \& Barr, M. (2002). Addressing the educational needs of boys (Report to the Department of Education, Science, and Training). Australia. Retrieved from http://www.xyonline.net/content/addressing-educationalneeds-boys-2002

Mansfield, H. C. (2006). Manliness. Binghampton, NY: Vail-Ballou Press.

Margonis, F. (2004). From student resistance to educative engagement: A case study in building powerful student-teacher relationships. In C. Bingham \& A. M. Sidorkin (Eds.), No education without relation (pp. 39-54). New York, NY: Peter Lang.

Marisuo-Storm, L. (2006). Girls and boys like to read and write different texts. Scandinavian Journal of Educational Research, 50(2), 111-125. 
Marsh, H. W., Martin, A. J., \& Cheng, J. H. (2008). A multilevel perspective on gender in classroom motivation and climate: potential benefits of male teachers for boys?. Journal of Educational Psychology, 100(1), 78-95.

Martin, A. J., \& Marsh, H. (2005). Motivating boys and motivating girls: Does teacher gender really make a difference? Australian Journal of Education, 49(3), 320-334.

Martino, W., Lingard, B., \& Mills, M. (2004). Issues in boys' education: A question of teacher threshold knowledge? Gender and Education, 16(4), 435-454.

Martino, W., \& Pallotta-Chiarolli, M. (2003). So what's a boy? Addressing issues of masculinity and schooling. Maidenhead, England: Open University Press.

Martino, W. (2008). Boys' underachievement: Which boys are we talking about? What Works?Research into Practice (Research Monograph \# 12). Retrieved from the Ontario Ministry of Education website: http://www.edu.gov.on.ca/eng/literacynumeracy/inspire/research/ martino.pdf

Moss, M. (2011). The media and the models of masculinity. Lanham, MD: Lexington Books.

Newkirk, T. (2002). Misreading masculinity: Boys, literacy, and popular culture. Portsmouth, NH: Heinemann.

Noguera, P. A. (2003). The trouble with Black boys: The role and influence of environmental and cultural factors on the academic performance of African American males. Urban Education, 38(4), 431-459.

Palmer, P. (1998). The courage to teach: Exploring the inner landscape of a teacher's life. San Francisco, CA: John Wiley \& Sons.

Renold, E. (2001). Learning the 'hard' way: Boys, hegemonic masculinity and the negotiation of learner identities in the primary school. British Journal of Sociology of Education, 22(3), 369-385.

Rezai-Rashti, G. M., \& Martino, W. (2010). Black male teachers as role models: Resisting the homogenizing impulse of gender and racial affiliation. American Educational Research Journal, 47(1), 37-64.

Roulsten, K., \& Mills, M. (2000). Male teachers in feminized teaching areas: Marching to the beat of the men's movement? Oxford Review of Education, 26(2), 221-227.

Ryan, J., Pollock, K., \& Antonelli, F. (2009). Teacher diversity in Canada: Leaky pipelines, bottlenecks, and glass ceilings. Canadian Journal of Education, 32(3), 591-617.

Sax, L. (2007). Boys adrift: Five factors driving the growing epidemic of unmotivated boys andunderachieving young men. New York, NY: Basic Books.

Skelton, C. (2001). Schooling the boys: Masculinities and primary education. Buckingham, England: Open University Press. 
Smithrim, K. (2000). Who will teach? In R. Upitis (Sr. Ed.), Who will teach: A case study of teacher education reform (pp. 13-25). San Francisco, CA: Caddo Gap Press.

Solomon, P. R. (1997). Race, role modelling, and representation in teacher education and teaching. Canadian Journal of Education, 22(4), 395-410.

Stewart, J., Meier, K. J., \& England, R. E. (1989). In quest of role models: Change in black teacher representation in urban school districts, 1968-1986. The Journal of Negro Education, 58(2), 140-152.

Tyre, P. (2008). The trouble with boys: A surprising report card on our sons, their problems at school, and what parents and educators must do. New York, NY: Three Rivers Press.

van Manen, M. (1991). The tact of teaching: The meaning of pedagogical thoughtfulness.London, ON: The Althouse Press.

van Manen, M. (2002). The tone of teaching. London, ON: The Althouse Press.

Weaver-Hightower, M. (2003). The "boy turn” in research on gender and education. Review of Educational Research, 73(4), 471-498.

Whitmire, R. (2010). Why boys fail: Saving our sons from an education system that's leaving them behind. New York, NY: AMACOM.

Winston, J. (2006). Beauty, goodness and education: The arts beyond utility. Journal of Moral Education, 35(3), 285-300. 